\title{
Conhecimentos e práticas de cuidados humanizados por equipe multiprofissional em
} Unidade de Terapia Intensiva-UTI coronariana

\author{
Knowledge and practices of humanized care by a multiprofessionall team in a coronary Intensive
} Care Unit-ICU

Conocimientos y prácticas de cuidados humanizados por un equipo multiprofesional en una Unidad de Cuidados Intensivos-UCI coronários

Recebido: 20/06/2021 | Revisado: 29/06/2021 | Aceito: 04/07/2021 | Publicado: 15/07/2021

\author{
Karliene Vieira Silva \\ ORCID: https://orcid.org/0000-0003-4790-1116 \\ Universidade Estadual do Ceará, Brasil \\ E-mail: karlienevieira@45.gmail.com \\ Annatalia Meneses de Amorim Gomes \\ ORCID: https://orcid.org/0000-0003-4793-6589 \\ Universidade Estadual do Ceará, Brasil \\ E-mail:annataliagomes@gmail.com \\ Maria Auxiliadora de Queiroz Maia \\ ORCID: https://orcid.org/0000-0002-0315-8693 \\ Universidade Estadual do Ceará, Brasil \\ E-mail: auximaia@gmail.com
}

\begin{abstract}
Resumo
A Humanização é fundamental para ultrapassar as barreiras das diferentes formas de relacionamento para a produção do cuidado humano. No contexto dos serviços de saúde, essa temática tem sido bastante enfatizada no ambiente hospitalar, porém pouco vista na prática. A pesquisa objetivou identificar os conhecimentos do cuidado humanizado por equipe multiprofissional em UTI coronariana, enfatizando os aspectos relacionados à ambiência, direito ao acompanhante durante a internação hospitalar e rotinas realizadas na UTI, através de um estudo exploratório descritivo com abordagem qualitativa, realizado na UTI Coronariana de um hospital público em Fortaleza-Ceará. Os dados foram coletados por meio de um questionário sociodemográfico/profissional e entrevista semiestruturada através da análise temática de Minayo. Participaram 03 Médicos, 05 Enfermeiros, 03 Fisioterapeutas e 05 Técnicos de Enfermagem. Surgiram como resultados seis categorias: "Humanização se aprende na prática"; "Empatia com todos"; "A rotina mecaniza o agir profissional"; "Acompanhante atrapalha, falta preparo"; "Ambiente silencioso e tranquilo"; e "Elementos para a qualificação dos trabalhadores". Constatou-se que a humanização do cuidado em UTIs é imprescindível para todos os envolvidos na dinâmica hospitalar. Os profissionais da saúde perceberam que é preciso aliar a tecnologia disponível à empatia e o cuidado no relacionamento interpessoal terapêutico para que ocorra a promoção do cuidado seguro e ético aos pacientes críticos. Além disto, foi destacado que o acompanhante oferece apoio e segurança para o paciente, sendo importante a sua presença, assim como a necessidade de aprimoramento contínuo da equipe como ferramenta básica para a prática da humanização.
\end{abstract}

Palavras-chave: Equipe de assistência ao paciente; Unidades de Terapia Intensiva; Acompanhantes de pacientes; Humanização da assistência hospitalar.

\begin{abstract}
Humanization is essential to overcome the barriers of different types of relationship for human care. In the context of health services, this matter has been heavily emphasized in the hospital environment, but not too much has been seen in practice. The objective of this work was to identify the knowledge of humanized care by a multidisciplinary team in a coronary ICU, focusing in aspects related to ambience, the right to have a companion during the hospitalization and routines performed in the ICU. The study was conducted with an exploratory qualitative approach, carried on in the Coronary ICU of a public hospital in the city of Fortaleza, state of Ceará. Data was collected through a sociodemographic/professional questionnaire and a semi structure interview, based on Minayo. Three doctors, five nurses, three physiotherapists and five nursing technicians participated. Six categories were identified: Humanization is learned in practice; Empathy with everyone; Routine mechanizes professional action; Companion hinders lack of preparation; Quiet and peaceful environment; and Elements for the qualification of workers. The study revealed that the humanization of healthcare in ICUs is essential for all health professionals in the hospital dynamics. The health professionals realized that it is necessary to combine available technology with empathy and care in the therapeutic interpersonal relationship so that safe and ethical care for critical patients can be promoted. In addition, it was
\end{abstract}


highlighted that the companion offers support and safety for the patient, since its presence is being important, as well as the need for continuous improvement of the team as a basic tool for the practice of humanization.

Keywords: Patient care team; Intensive Care Units; Patient companion; Humanization of hospital care.

\section{Resumen}

La humanización es fundamental para superar las barreras de los diferentes tipos de relación para el cuidado humano. En el contexto de los servicios de salud, este tema se ha enfatizado mucho en el ámbito hospitalario, pero no se ha visto demasiado en la práctica. El objectivo del trabajo fue identificar el conocimiento del cuidado humanizado por parte de un equipo multidisciplinario en una UCI coronaria, enfocándose en aspectos relacionados con el ambiente, el derecho a tener un acompañante durante la hospitalización y las rutinas realizadas en la UCI. El estudio se realizó con abordaje exploratorio cualitativo, realizado en la UCI Coronaria de un hospital público de la ciudad de Fortaleza, estado de Ceará. Los datos se recolectaron a través de un cuestionario sociodemográfico / profesional y una entrevista semiestructurada, con base en Minayo. Participaron tres médicos, cinco enfermeras, tres fisioterapeutas y cinco técnicos de enfermería. Se identificaron seis categorías: La humanización se aprende en la práctica; Empatía con todos; La rutina mecaniza la acción profesional; Acompañante dificulta la falta de preparación; Ambiente tranquilo y apacible; y Elementos para la calificación de los trabajadores. El estudio reveló que la humanización de la asistencia sanitaria en las UCI es fundamental para todos los profesionales sanitarios, con el uso de la tecnología disponible, combinándose con la empatía por la asistencia sanitaria basada en las relaciones interpersonales terapéuticas, con el objetivo de promover una atención segura y ética a los pacientes críticos. Los participantes manifestaron que el acompañante brinda apoyo y comodidad al paciente, y su presencia es importante. También es necesario la mejora continua del equipo como herramienta básica para la práctica de la humanización.

Palabras clave: Equipo de atención al paciente; Unidades de Cuidados Intensivos; Acompañante del paciente; Humanización de la atención hospitalaria.

\section{Introdução}

A Unidade de Terapia Intensiva (UTI) se configura como um local de prestação de cuidados a pacientes em estado crítico de saúde, com equipamentos sofisticados e recursos humanos especializados (Mongiovi et al., 2014). Dentro deste contexto, o ambiente da UTI é considerado estressante pelos pacientes, familiares e pela equipe de profissionais no setor. Isto possivelmente ocorre em decorrência da constante tensão e das situações iminentes de emergência e instabilidade.

As UTIs são vistas muitas vezes como locais de preocupação e medo, com uma imagem de unidade fechada e restrita ao acesso para os familiares (Goularte, Gabarra \& Moré, 2020). Alguns estudos reconhecem que as famílias são um recurso valioso para reduzir os sintomas de estresse, ansiedade e depressão provocados pelo estado crítico dos pacientes. Dentro desta mesma linha de pensamento, no que diz respeito aos familiares, Reis, Gabarra e Moré (2016) acreditam que a família é parte integrante do paciente internado em UTI, onde o horário de visita é visto como um dos momentos de maior expectativa pelos familiares. As mudanças decorrentes da hospitalização de um dos membros da família são significativas e podem interferir em toda a dinâmica familiar, desta forma, refletindo no cotidiano de todos os envolvidos (Goularte et al., 2020).

Neste contexto, Camponogara, Santos, Seiffert e Alves (2011) destacam que o ambiente da UTI "transparece gravidade" devido ao risco de morte dos pacientes e das práticas invasivas e tensas sendo, portanto, caracterizado como uma unidade de cuidados geradora de distúrbios emocionais e psicológicos nos pacientes, familiares e profissionais. Além disso, há também um predomínio de sensações de dor e angústia no imaginário do paciente (Silveira \& Contim, 2015).

Embora a complexidade do conhecimento biomédico, o avanço tecnológico e a melhoria do cuidado em saúde terem possibilitado a criação das UTIs, com o passar do tempo estas se tornaram um lugar onde a técnica tem se sobressaído em relação aos aspectos dos cuidados, pois os profissionais estão tão envolvidos com as máquinas, monitores e técnicas rotineiras que tendem a esquecer a existência do paciente e sua família (Costa, Figueiredo \& Shaurich, 2009).

De acordo com Pessini, Bertachini e Barchifontaine (2014), na área da saúde o termo humanização tem sido usado com vários significados e entendimentos diferentes, que com o passar do tempo vem se modificando continuamente. No contexto atual, a humanização é vista como um movimento de integração das relações da saúde, visando um atendimento de qualidade e um ambiente mais propício para o incremento do cuidado. 
Felizmente, desde 2003 com a Política Nacional de Humanização (PNH), cada vez mais se verifica a importância do acolhimento ao paciente e familiares, além da necessidade de incluí-los no processo de cuidado, do valor da comunicação e do adequado relacionamento interpessoal entre estes e a equipe (Goularte et al., 2020). O fato é que a PNH, assim como os princípios e diretrizes do Sistema Único de Saúde (SUS), se comprometem em possibilitar atenção integral à população e propor estratégias que viabilizem a ampliação das condições de direitos e cidadania. Além dos princípios da PNH, ainda existem as diretrizes e dispositivos que funcionam como norteadores das ações de humanização no SUS.

A humanização deve fazer parte do pensar e agir da equipe de profissionais em todos campos da saúde e, especialmente, nas UTIs. Os recursos materiais e instrumentais são muito fundamentais na UTI, mas não devem suplantar as necessidades biopsicossociais, espirituais e ambientais dos pacientes e suas famílias (Camponogara et al., 2011).

Nesse âmbito, surgiram os questionamentos advindos do contato e da vivência diária do trabalho na UTI Coronariana: qual a visão da equipe multiprofissional a respeito do cuidado humanizado? Como é desenvolvida esta prática na UTI coronariana? Quais os elementos que poderiam contribuir para a qualificação da equipe multiprofissional para um cuidado humanizado? Quais as reflexões da equipe acerca da ambiência, presença do acompanhante durante a hospitalização e rotinas de trabalho?

Diante disso este estudo visa a análise dos conhecimentos e práticas de cuidados humanizados realizados por profissionais em uma UTI coronariana de um hospital público de Fortaleza, no sentido de responder aos questionamentos citados anteriormente.

\section{Metodologia}

Este estudo é do tipo descritivo exploratório, aplicado à observação e à descrição de um fenômeno, investigando a sua natureza complexa e os fatores com os quais está relacionado, com abordagem qualitativa, consoante à análise temática proposta por Minayo (Leopardi, 2001).

O estudo foi desenvolvido na UTI Coronariana de um hospital público do município de Fortaleza-Ceará. O público alvo foi a equipe multiprofissional que trabalha no período do plantão diurno. Os critérios de inclusão da pesquisa foram: profissionais da equipe (médicos, fisioterapeutas, enfermeiros e técnicos de enfermagem); aqueles que concordaram com o termo de consentimento livre e esclarecido; e aqueles com mais de três anos de tempo de serviço nessa UTI.

A amostra se baseou na perspectiva qualitativa, não se orientando pelo critério numérico para garantir representatividade, pois segundo Minayo, Deslandes e Gomes (2015), para uma amostra ser considerada ideal, ela deve refletir a totalidade do problema investigado em suas múltiplas dimensões. A amostra final foi constituída por um total de 16 profissionais de saúde, composto: 05 Enfermeiros, 05 Técnicos de Enfermagem, 03 Fisioterapeutas; e 03 Médicos.

Os dados foram colhidos após o esclarecimento dos profissionais e assinatura no Termo de Consentimento Livre e Esclarecido (TCLE), bem como após a aprovação do projeto pelo Comitê de Ética do hospital Dr. Carlos Alberto Studart Gomes e pela Universidade Estadual do Ceará, com o parecer número 1.631.015.

A coleta dos dados ocorreu no período de setembro a novembro de 2017, por meio de um formulário de caracterização sociodemográfico/profissional e entrevista semiestruturada. Foi aplicado um pré-teste com três profissionais da equipe, para validação da qualidade do instrumento de coleta, tendo sido excluídos da pesquisa os entrevistados do pré-teste. As respostas foram gravadas e as entrevistas transcritas integralmente. No perfil sociodemográfico/profissional extraíram-se dados como: sexo, estado civil, faixa etária, categoria profissional, tipo de vínculo com o hospital, tempo de formação, maior titulação, confirmação da especialidade em UTI, tempo de trabalho em UTI e tempo de trabalho na UTI Coronariana do hospital local da pesquisa. A entrevista semiestruturada obedeceu a um roteiro com 6 questões abertas, como: "Diga-me o que 
você entende por humanização na assistência em UTI Coronariana?"; "Como se deu a sua formação profissional nos aspectos relacionados a humanização do cuidado ao paciente?"; "Como você percebe o ambiente da UTI Coronariana?”; "Descreva a presença do acompanhante na UTI Coronariana?"; "Comente sobre a rotina dos procedimentos na UTI Coronariana"; e "Sugestões para a humanização na UTI Coronariana".

A etapa de coleta de dados foi encerrada quando se encontrou um nível de saturação, onde o critério de confiabilidade das informações recebidas foi considerado suficiente para responder todos os questionamentos. Para assegurar o anonimato, foi atribuído um codinome aos entrevistados do estudo: PM (Profissional Médico), PE (Profissional Enfermeiro), PF (Profissional Fisioterapeuta) e PT (Profissional Técnico de Enfermagem).

A classificação e consolidação dos dados foram alocadas em categorias que conduziram à especificação dos temas.

\section{Resultados e Discussões}

De acordo com os dados sociodemográfico/profissional, foram observados que 81,5\% dos entrevistados são do gênero feminino; $56,25 \%$ são cooperados; $12,5 \%$ possuem título de mestre; a maioria dos profissionais está na faixa etária entre trinta e quarenta anos, o que caracteriza uma equipe jovem e com certa vivência, pois já possuem mais de três anos de experiência em UTI; além do tempo de formação, acima de dez anos.

Foram identificadas seis categorias: "Humanização se aprende na prática"; "Empatia com todos"; "A rotina mecaniza o agir profissional"; "Acompanhante atrapalha, falta preparo"; "Ambiente silencioso e tranquilo" e "Elementos para a qualificação dos trabalhadores".

\section{Categoria 1- Humanização se aprende na prática - "Eu vim aprender, mesmo no decorrer da minha profissão, na prática do dia a dia”}

Em relação ao perfil de formação profissional, a maior parte dos entrevistados da pesquisa relatou que durante o curso houve alguma abordagem sobre humanização, mas não havia disciplina específica sobre o tema, com maior destaque para a parte técnica. Isso ratifica o fato de os cursos ainda apresentarem uma grande carência sobre a temática, apesar das diretrizes curriculares para a área da saúde primarem pelos aspectos éticos humanistas na capacitação de competências, habilidades gerais e específicas, sob o ponto de vista da integralidade da assistência.

"Não...ele [o curso técnico de enfermagem] foi mais técnico mesmo...mais medicação" (PT2).

"Infelizmente não teve nenhuma disciplina específica [no curso técnico de enfermagem] sobre isso...na verdade a gente vem mesmo vê na prática" (PT1).

Em um determinado momento, um dos técnicos de enfermagem destacou que os cursos técnicos são mais práticos e que adquiriu mais conhecimento sobre a prática de cuidados humanizados em cursos de educação continuada, palestras e cursos de curta duração, que aconteciam em outro hospital onde já havia trabalhado. Nessa direção, a formação dos profissionais da saúde necessita de ampliação da base conceitual dos estudantes, mediante entendimento do processo saúdedoença como fenômeno complexo e não restrito somente ao campo biológico. Isto é importante para que a idealização e cuidado do paciente não se limitem a um discurso puramente teórico, desarticulado das práticas de cuidado (Casate \& Correa, 2012).

Alguns profissionais se referiram a uma interação entre o corpo físico e o psicológico, demonstrando uma visão mais abrangente acerca do cuidado na assistência, por considerarem os aspectos psicossociais envolvidos na dinâmica dos pacientes. Deixar o paciente mais à vontade e se sentindo em casa, como foi mencionado logo abaixo, denota o cuidado mais sensível e humano por parte do profissional. 
"[...] interagir com o paciente, tanto a parte física como a psicológica, e ali a gente trabalha o corpo e a mente [...] deixar o paciente mais à vontade, deixá-lo se sentindo em casa [...] e nessa dinâmica a gente acaba se relacionando com o paciente e de certa forma se tornando uma família (PT4).

Nesse mesmo entendimento, foi observado em uma das falas dos entrevistados, o fato de muitos profissionais que resolvem trabalhar na assistência e na saúde trazerem consigo essa característica da preocupação em prestar uma assistência mais humanizada, com um cuidado de visão global e de interação corpo e mente.

“[...] na hora que eu fiz a opção pela área da saúde en já me sinto diferente, já me sinto uma pessoa que se importa com o outro e isso já é o início da humanização" (PF3).

Diante deste cenário, percebe-se pelos relatos dos entrevistados da pesquisa, que em muitos cursos de graduação e de formação técnica em saúde ainda há lacunas a serem preenchidas sobre os aspectos ou temas relacionados à Humanização e à PNH, com ênfase na singularidade e subjetividade do paciente, bem como o protagonismo dos trabalhadores da saúde, a partir do seu campo empírico (Pinho, Siqueira \& Pinho, 2006).

É relevante destacar que a orientação dos profissionais da saúde durante a graduação é fundamental, não só em relação ao aspecto do cuidado humanizado, mas também a relação imprescindível que existe entre a equipe e a importância de cada um naquele ambiente. Este fato está alinhado com os pensamentos de Chernicharo, Silva e Ferreira (2011), quando destacam que temas do cotidiano devem ser discutidos pela equipe, para que a Humanização possa ser vivenciada na forma prática e não só repassada na teoria.

\section{Categoria 2- Empatia com todos - "É você fazer o diferencial, não só pelo paciente, mas pela família e o todo, se colocando no lugar dele"}

Durante as entrevistas, dentre as concepções de humanização que emergiram, identificou-se o cuidado expresso, em uma visão sentimental e no modo de tratar o paciente, destacando a abordagem, o atendimento e o acolhimento do paciente de forma sensível, considerando suas necessidades e suas fragilidades.

"Humanizar é você tentar olhar esse lado do paciente também, ver o lado emocional, chamar a pessoa pelo nome, se preocupar com o conforto não só dele, mas da própria família [...]” (PM1).

"[...] humanização parte do princípio de você se colocar no lugar do outro, e a partir disso você tem que ver que o paciente está fragilizado, no seu momento de fraqueza, então quanto mais você ouvir, quanto mais você interagir com ele e der uma palavra de conforto, melhor para esse paciente [...]" (PE5).

Pensamentos que remetem ao entendimento de Carlos, Rodrigues e Souza (2004), consideram a humanização como uma ação solidária, o silêncio que comunica, um sorriso que pode alegrar e a dúvida que pode ser desfeita através do esclarecimento, trazendo o reestabelecimento da confiança.

Diante dos pensamentos dos profissionais, voltado mais para a questão da sensibilidade, ressalta-se a postura do profissional, em detrimento do próprio conceito teórico de humanização, haja vista envolver um contexto maior do que simplesmente tratar bem o paciente. Para Camponogara e colaboradores (2011), a humanização é estabelecida como forma de resgatar a dignidade humana, mas somente será realidade quando sua importância real for compreendida, assim como quando os profissionais se sentirem protagonistas desse processo na UTI coronariana.

"É tratar os pacientes que estão ali como verdadeiros seres humanos e não como máquinas, jamais esquecer que aquele que está ali é um ser humano [...]" (PT4). 
"É você ouvir o paciente, quanto mais você interagir com ele, orientá-lo, dizer o dia da semana e dar uma palavra de conforto [...]" (PE5).

A comunicação também foi outro ponto destacado por alguns profissionais, como sendo uma das ferramentas necessárias para entender o que efetivamente o paciente necessita e o que está sentindo. A comunicação tem sido um elemento fundamental para a compreensão da humanização (Goulart \& Chiara, 2010), pois a comunicação propicia o desenvolvimento de uma rede de significados entre o paciente, a equipe e a família.

Diante do exposto, o que se pode depreender através das falas dos entrevistados é que a maioria dos profissionais que trabalham com saúde e com pessoas, principalmente em uma UTI Coronariana, age com certo cuidado, tornando a dinâmica harmoniosa, o que favorece a humanização, onde todos se preocupam em primeiro lugar com o paciente, seu bem-estar e suas necessidades. Neste instante, verifica-se a importância do trabalho em equipe de forma interdisciplinar, pensando sempre no melhor para o paciente, sendo resolutivo e com uma interação satisfatória.

\section{Categoria 3- Acompanhante atrapalha, falta preparo - "Acompanhante para o paciente é importante, mas na maioria} das vezes atrapalha, a família não tem preparo"

A presença do acompanhante se mostrou polêmica, com base na percepção de cada profissional durante a realização das entrevistas. Entretanto, de uma maneira geral, foi apresentada de forma enfática em relação a duas opiniões registradas por praticamente todos os entrevistados da pesquisa, no sentido de que é positiva para o paciente a presença do acompanhante, mas não para a equipe.

"[...] é bom no caso de um idoso por que ele sofre muito no ambiente que ele não conhece...com pessoas desconhecidas, então ele tende a ficar desorientado comprometendo até o tratamento dele" (PT4).

“O acompanhante para o paciente é importante, eles se sentem mais seguros, mais confiantes [...]” (PE4).

"[...] pra gente não é bom porque a gente não se sente à vontade de fazer os procedimentos, as medicações, eles ficam perguntando sempre o que é, aí tudo aquilo ali causa uma situação ruim, atrapalha" (PT2).

Por meio dos estudos de Knobel, Andreoli e Erlichman (2008), tornou-se evidente que a presença do acompanhante pode reduzir a ansiedade e o medo, contribuindo para a recuperação do paciente. Este estudo vem comprovar a importância da presença do acompanhante para o conforto, segurança e apoio do paciente. Os autores entendem que em alguns casos se torna até necessária essa presença, como, por exemplo, para o idoso e para aqueles pacientes relutantes em aceitar o tratamento.

É importante destacar que os pacientes se comportam de maneira diferente na presença da família, podendo contribuir positivamente para o tratamento, visto que aceitam com mais facilidade as rotinas terapêuticas. Entende-se, dessa forma, que para eles a presença do acompanhante proporciona segurança e apoio emocional.

Este aspecto também é observado na fala de uma enfermeira, quando diz: “[...] a família passa aquela força, aquela energia boa, calor que só a família tem". O acompanhante vem sendo visto como facilitador da recuperação do paciente e do processo de reabilitação, tendo a capacidade de estabelecer vínculos afetivos e suporte emocional, devido ao valor dado à presença de alguém no processo do cuidado (Neves et al., 2018).

Os benefícios da visita para pacientes e familiares são abordados em outros estudos que ressaltam a importância das instituições possuírem políticas abertas ou pelo menos mais flexíveis em relação à visitação (Beccaria et al., 2008; Ramos et al., 2014). Os familiares de pacientes internados em UTI precisam de informações claras, para que sejam minimizados os efeitos da ansiedade que possam gerar interpretações errôneas e uma má comunicação com a equipe. 
"A família não sabe e não tem noção, então ela interpreta de outra forma, um acesso, uma intubação, uma contenção que o paciente precisa usar, a família tem que vir para a UTI já sabendo o que se deve e o que não deve fazer" (PE1).

"Tem que ser uma coisa adaptada, multiprofissional, com uma comunicação efetiva e amadurecimento. Antes precisa-se de vários instrumentos para colocar aquele acompanhante para o paciente” (PE1).

Diante destas falas, foi enfatizada por todos a importância do acompanhante desde que esteja bem preparado para permanecer num ambiente de UTI, pois a complexidade deste ambiente precisa ser entendida para que não ocorram situações distorcidas, onde o acompanhante interprete erroneamente as situações de risco e os procedimentos que precisam ser realizados. Dentro deste contexto, a Cartilha HumanizaSUS (Brasil, 2010) ressalta que o acompanhante é importante não só para estar com o ente internado, mas também para ser orientado no seu papel de cuidador leigo.

Outro fato destacado pela equipe é que, na maioria das vezes, o acompanhante, pelo seu despreparo, não obedece às regras da UTI coronariana e ultrapassa os limites que são impostos para a sua presença. Desta forma, podem ocorrer atritos com a equipe em algumas situações, como por exemplo a manipulação das bombas de aplicação de medicamentos, uso do celular e o trânsito indevido entre os leitos.

"O acompanhante ficar transitando dentro da UTI com telefone, isso atrapalha um pouco a gente [...]" (PE3).

"Muitas vezes, eles não respeitam as regras da UTI coronariana, usam o celular, tiram fotos, e até mexem nas bombas [...] isso atrapalha muito nosso serviço" (PT5).

$\mathrm{Na}$ verdade, a família não entende certos procedimentos executados rotineiramente e terminam por questionar, entendendo que aquela situação é errônea, tornando a internação do paciente cada vez mais complicada.

“[...] pra gente não é bom porque a gente não se sente à vontade de fazer os procedimentos, eles perguntam muito, acho constrangedor, parece que não confiam na gente" (PT1).

"O acompanhante não sabe separar que ele é só acompanhante e acaba querendo assumir o papel da enfermagem, "batendo de frente" com os profissionais" (PE4).

Todos estes aspectos relatados pela equipe, corroboram com os estudos de Vedootto e Silva (2010), quando defendem que o profissional da saúde enxerga o acompanhante como um "peso", obstruindo e atrapalhando o desenvolvimento do trabalho.

\section{Categoria 4 - A rotina mecaniza o agir profissional e potencializa a humanização - "As rotinas acabam sendo coisa do dia a dia, a gente faz mesmo que mecanicamente"}

As rotinas são procedimentos que acontecem continuamente no ambiente de UTI. Os profissionais as realizam por dias a fio, sendo que na UTI coronariana são destacadas a hora do banho, mudanças de decúbito, o momento da higiene oral, os horários das medicações, da fisioterapia, do curativo realizado pela equipe de enfermagem, a avaliação médica e a hora da visita. Esta última é classificada como o melhor momento, pois os pacientes se sentem acolhidos e mais seguros, pela presença dos seus familiares.

As ações de assistência, quando humanizadas, centralizam-se não apenas na recuperação e na cura do paciente crítico, mas também no seu bem-estar completo, sendo essencial ouvi-lo e considerá-lo nos aspectos emocionais, psicológicos e afetivos. (Reis, Sena \& Fernandes, 2016). De acordo com algumas falas, houve destaque para a forma de tratar o paciente, afirmando como cada um gosta de ser tratado. Neste sentido, houve novamente um destaque na questão do cuidado 
humanizado direcionado para o ser de cada um e como é aplicado pelos profissionais durante as rotinas, sendo que a grande maioria as realiza de acordo com o que acha correto, com humanização durante as rotinas, no caso de aquele profissional ser uma pessoa sensível e emotiva.

"Existem pessoas que parecem menos amáveis, mas não são, é a maneira como elas são, a secura no tom da voz perturba algumas pessoas, principalmente aquelas que estão mais vulneráveis à tristeza, devido a doença que há pouco descobriram, mas há também pessoas que tem a voz firme e mesmo assim podem ser sensíveis, é uma questão pessoal, independente do tom de voz, a sensibilidade é própria da pessoa, é uma questão intrínseca” (PE1).

Ainda dentro do contexto da equipe, durante a realização das rotinas foi comentado sobre tarefas que envolviam uma maior necessidade de força por parte dos profissionais, como a mudança de decúbito e a hora do banho, que eram realizadas mecanicamente e de "má vontade" por alguns deles.

"Tem gente que acha que vem pra cá pra dar o recado dela e ir embora" (PM1).

"Em relação às rotinas, acaba sendo coisa do dia a dia, a gente faz mesmo que mecanicamente, não tem essa questão de humanização em relação a isso aí, o banho [...] vira tudo muito mecânico" (PT1).

Backes, Erdmann e Backes (2012) asseveram que os profissionais da UTI criam um mecanismo de adaptação ao trabalho e acabam, muitas vezes, não se sensibilizando mais com o sofrimento e a condição de saúde dos pacientes. Devido a isso, começam a cuidar dos pacientes de forma rotineira e mecanizada, priorizando somente a dimensão biológica. Outra atividade destacada pelos entrevistados, realizada de forma mecânica, é a hora das admissões dos pacientes, pois seguem um protocolo, recebem, se apresentam, monitorizam e medicam, estando a família em segundo lugar. O tempo não permite um acolhimento melhor, "é corrido demais ", dizem eles.

Mesmo diante das falas frequentes sobre mecanização do trabalho, houve destaque também para o trabalho em equipe, de forma harmoniosa e sincronizada, tentando evitar a mecanicidade, principalmente quando os profissionais têm afinidades pessoais em comum.

“[...] é o trabalho entre pessoas com pensamento diferentes, mas o ser humano é muito fácil de se adaptar e romper com essas barreiras" (PT5).

Ressalta-se, portanto, que para ocorrer a humanização no processo de trabalho, deve existir autonomia nos comportamentos e ações, bem como respeito ao protagonismo de cada sujeito, para que as relações existentes sejam fortalecidas de maneira harmônica, envolvendo profissionais, pacientes, a família e a instituição. Isso torna possível a promoção da qualidade da assistência nos serviços de saúde, sobretudo no contexto hospitalar (Bastos, 2016).

Para grande parte dos entrevistados, a hora do banho é um momento difícil, tanto para o paciente como para o próprio profissional que o executa. Por isso, são imprescindíveis o respeito e a sensibilidade do profissional em preservar o mesmo gênero para os cuidados com o paciente, tornando o momento menos difícil e mais tranquilo.

"Ás vezes o paciente não quer ser banhado naquele horário, tem que ser respeitado também né, a equipe é muitas vezes resistente, eu não vou mentir, mas na medida do possível a gente flexibiliza” (PE2).

"Na hora do banho, se ele não quiser a gente conversa, fala que é morninho, é uma abordagem muito dinâmica e bem humanizada e se for do outro sexo, a gente respeita, mas só quando ele solicita" (PT5). 
Categoria 5- Ambiente silencioso e tranquilo - "Aqui devia ser um ambiente mais silencioso, as pessoas têm que ter mais consciência, deixar aqui mais tranquilo".

O termo ambiência na Saúde refere-se ao tratamento dado ao espaço físico, compreendido como espaço social, profissional e das relações interpessoais que devem proporcionar atenção acolhedora, resolutiva e humana (Brasil, 2010). Também há fatores relacionados à ambiência que necessitam ser destacados como os relacionados ao conforto para o paciente e para equipe, além da presença de um bom espaço para repouso e alimentação. Para os familiares, é importante um local de espera adequado para o horário da visita. A segurança do paciente também é um fator ligado a ambiência, principalmente relacionada aos riscos de acidentes como quedas que eventualmente possam acontecer.

Vários foram os discursos dos profissionais em relação à ambiência da UTI Coronariana, sendo que muitas relacionadas ao ambiente físico.

"Ela não é a melhor, mas ela tem alguns pontos positivos, um deles é o espaço, a acomodação individual de cada paciente, cada leito tem uma janelinha que dá pra esse paciente ver, quando ele tiver mais orientado, se é dia ou noite" (PM1).

“Aqui a grande diferença é que você tem uma distância ideal entre os pacientes, eles são separados por paredes que dá mais privacidade na hora da higiene, ele se sente ali na casinha dele protegido. Para os profissionais, a estrutura física também é boa” (PM2).

No que se refere à ambiência, a PNH defende que um ambiente acolhedor, resolutivo e humano na Unidade de Terapia Intensiva, é de extrema importância para a garantia de privacidade e conforto, tanto dos usuários como dos profissionais, o que repercute no cuidado oferecido (Reis et al., 2016). Embora os profissionais da UTI coronariana tenham destacado as dimensões espaciais e estrutura, também ressaltaram elementos desfavoráveis, tais como:

“É preciso colocar mais relógios perto dos leitos para que os pacientes tenham uma orientação melhor, como o horário do dia, por que eles perdem essa referência e apresentam muito desorientação” (PM3).

"O ambiente também deveria ser mais ensolarado, um acesso melhor à iluminação natural, para que o paciente possa ver em que turno do dia ele se encontra, sobre o conforto de uma forma geral, acredito que os leitos atuais são modernos" (PM3).

Para a Cartilha HumanizaSUS (Brasil, 2010), referente à ambiência, a iluminação natural deve ser garantida em todos os ambientes, lembrando sempre que toda pessoa tem direito à noção de tempo - dia e noite, chuva ou sol - e que isto pode influenciar no seu estado de saúde. Essa influência pode estar relacionada ao "delirium”, fato observado constantemente no ambiente de Terapia Intensiva. Diante de todos os fatores citados pelos entrevistados, houve um destaque para o desconforto, as conversas em voz alta da equipe e o barulho constante.

“Já tem os barulhos das bombas, monitor, e aí é muita gente conversando, acaba que o pessoal esquece um pouco que está nesse ambiente, parece que estão numa feira” (PM2).

"Acho essa UTI muito barulhenta, muito agitada, os pacientes reclamam muito disso, eu acho que deveria ter mais humanização das pessoas neste sentido" (PT2).

A grande maioria comentou que a UTI era bastante barulhenta, talvez pela questão da amplitude do ambiente, além do fato de os profissionais não terem o cuidado de dialogar próximo a outro(s). Dessa forma, elevavam a voz sem perceber o quanto tornavam o ambiente perturbador para o paciente e para própria equipe. Para muitos, seria um desrespeito à condição 
do paciente, uma vez que já existem os ruídos dos monitores e das bombas, que deixam o ambiente estressante e pouco confortável, tanto para os pacientes como para os profissionais.

Categoria 6- Elementos para a qualificação dos trabalhadores - "É preciso inteligência emocional para trabalhar com o ser humano"

$\mathrm{Na}$ finalização da entrevista, os entrevistados ficaram bem à vontade durante seus discursos. Inúmeras foram as sugestões para o desenvolvimento de uma nova rotina que focasse em humanização. A partir desta etapa do estudo, a equipe já fazia questionamentos sobre o tema de uma forma diferente, estando mais sensibilizada e reflexiva, apresentando contrapontos e, em maior destaque, os benefícios que existem para todos que participam da dinâmica da assistência em realizar o cuidado humanizado.

Existem vários fatores que podem contribuir para a não realização de uma assistência humanizada em UTI, como a participação cada vez menor dos profissionais nas decisões, a escassez da mão de obra qualificada e os baixos investimentos na educação continuada, criando assim um contraste da atual realidade com suas estratégias (Reis et al., 2016). A realização de cursos de qualificação e treinamentos foi constantemente citada por todos. Nesse sentido, entende-se que para o trabalho na UTI se tornar mais humanizado, é preciso investir em cursos e capacitação, para despertar uma maior dedicação e cooperação entre os profissionais sobre esse tema.

Diante disso, entende-se que para a humanização existir no serviço hospitalar, em especial na UTI, os profissionais precisam conscientizar-se da necessidade de aprimoramento, associando as evoluções tecnológicas ao diálogo e solidariedade em tempo integral. É preciso que a humanização seja sentida por todos: pacientes, familiares e equipe de saúde, sendo que cada processo de humanização é único e singular e depende de cada profissional e de cada equipe. Portanto, se a própria equipe de saúde não perceber sua importância dentro desse processo, não será possível a transformação e humanização das relações (Reis et al., 2016).

Conforme Quadro 1, destacam-se sugestões pelos profissionais que participaram da pesquisa, para a humanização das práticas de cuidados humanizados em UTI Coronariana.

Quadro 1- Sugestões destacadas pela equipe da UTI coronariana.

\begin{tabular}{|ll|}
\hline Profissionais & \multicolumn{1}{c|}{ Sugestões } \\
\hline PE1 & Comunicação efetiva com o paciente e a família \\
PF1 & Qualificar a equipe \\
PF1 & Encontros entre os profissionais \\
PF1 & Treinamentos \\
PT2 & Apoio Psicológico \\
PE2 & Cooperação de todos \\
PE2 & Descanso para os profissionais \\
PM2 & Flexibilizar mais as rotinas \\
PM2 & Diminuir o barulho \\
PM3 & Cursos de capacitação \\
PM3 & Melhorar iluminação natural \\
PT3 & Colocação de relógios \\
PE3 & Reuniões e palestras \\
PF3 & Melhorar o acolhimento \\
PT5 & Presença do Serviço Social \\
\hline
\end{tabular}

Fonte: Elaborado pelas autoras. 


\section{4- Considerações Finais}

Por meio desse estudo, foi possível constatar que, para a humanização do cuidado em UTI acontecer, é imprescindível que todos os profissionais de saúde do setor utilizem a tecnologia disponível, juntamente com a empatia, embora tenha se observado que alguns profissionais não apresentaram conhecimento amplo sobre a temática. A importância desse assunto foi valorizada pelos participantes da pesquisa, com destaque para a presença do acompanhante, desde que esteja bem orientado e acompanhado pela equipe.

Em relação à ambiência, é preciso que exista um ambiente silencioso, adequado, acolhedor e confortável para pacientes, familiares e profissionais. Também é necessário um relacionamento interpessoal terapêutico para que ocorra a promoção do cuidado seguro, responsável e ético aos pacientes. Ademais, foi evidenciada a necessidade de um aprimoramento contínuo da equipe por meio de cursos de educação permanente e continuada, para que o cuidado humanizado na UTI se estabeleça aos poucos.

É importante destacar que o ritmo agitado existente na UTI onde foi desenvolvido o estudo, pode ser considerado um fator limitante para pesquisa em relação ao número de participantes. Mesmo assim, os objetivos foram alcançados de acordo com as considerações feitas pelos participantes, já que todos acreditam na necessidade do cuidado humanizado na prática hospitalar para a promoção da saúde.

\section{Referências}

Backes, M. T. S., Erdmann, A. L., \& Backes, D. S. (2012). O cuidado intensivo oferecido ao paciente no ambiente de Unidade de Terapia Intensiva. Esc. Anna Nery. 16(4), 689-696. https://doi.org/10.1590/S1414-81452012000400007.

Bastos, E. A. (2016). Saberes e práticas dos trabalhadores da saúde para humanização do cuidado em maternidade pública. Dissertação de Mestrado, Universidade Estadual do Ceará, Fortaleza, CE, Brasil. http://siduece.uece.br/siduece/trabalhoAcademicoPublico.jsf?id=85190.

Beccaria, L. M., Ribeiro, R., Souza, G. L., Scarpetti, N., Contrin, L. M., Pereira, R. A. M., \& Rodrigues, A. M. S. (2008). Visita em Unidades de Terapia Intensiva: concepção dos familiares quanto à humanização do atendimento. Rev Arq Ciênc Saúde. 15(2), 65-9. https://repositorio-racs.famerp.br/racs_ol/vol15-2/id\%20263.pdf.

Brasil. (2010). Ministério da Saúde. Secretaria de Atenção à Saúde. Núcleo Técnico da Política Nacional de Humanização. HumanizaSUS: visita aberta e direito a acompanhante / Ministério da Saúde, Secretaria de Atenção à Saúde, Núcleo Técnico da Política Nacional de Humanização. - 2. ed. 4. reimp. Brasília: Ministério da Saúde. 32 p.: il. - (Série B. Textos Básicos de Saúde) ISBN 978-85-334-1339-9.

. (2011). Ministério da Saúde. Secretaria de Atenção à Saúde. Departamento de Ações Programáticas e Estratégicas. Atenção hospitalar / Ministério da Saúde, Secretaria de Atenção à Saúde, Departamento de Ações Programáticas e Estratégicas. - Brasília: Ministério da Saúde, 268 p.,: il. - (Série B. Textos Básicos de Saúde) (Cadernos HumanizaSUS). ISBN 978-85-334-1760-1.

Camponogara, S., Santos, T. M., Seiffert, M. A., \& Alves, C. N. (2011). O cuidado humanizado em Unidade de Terapia Intensiva: uma revisão bibliográfica. R. Enferm. UFSM. 1(1), 124-132. doi: https://doi.org/10.5902/217976922237.

Carlos, C. L., Rodrigues, C. M. C., \& Souza, G. F. (2004). Humanização na unidade de terapia intensiva: enfermeira, paciente e família. Revista Brasileira de Ciências da Saúde. 2(3), 11-16. https://seer.uscs.edu.br/index.php/revista_ciencias_saude/article/view/475/324.

Casate, J. C., \& Correa, A. K., A. (2012). Humanização do cuidado na formação dos profissionais de saúde nos cursos de graduação. Rev Esc Enferm USP. 46(1), 219-226. https://www.scielo.br/j/reeusp/a/c5CW7WD9pXtCvYY5przScJd/?lang=pt\&format=pdf.

Chernicharo, I. M., Silva, F. D., \& Ferreira, M. A. (2011). Humanização no cuidado de enfermagem nas concepções de profissionais de enfermagem. Esc Anna Nery Rev Enferm. 15(4), 686-693. https://www.redalyc.org/pdf/1277/127721087005.pdf.

Costa, S. C., Figueiredo, M. R. B., \& Shaurich, D. (2009). Humanização em Unidade de Terapia Intensiva Adulto (UTI): compreensões da equipe de enfermagem. Interface- comunicação, Saúde, Educação. 13(1), 571-580. https://doi.org/10.1590/S1414-32832009000500009.

Goulart, B. N. G., \& Chiari, B. M. (2010). Humanização das práticas do profissional de saúde: contribuições para reflexão. Ciênc. saúde coletiva. 15(1), 255268. https://doi.org/10.1590/S1413-81232010000100031.

Goularte, P. N., Gabarra, L. M., \& Moré, C. L. O. (2020). A visita em Unidade de Terapia Intensiva adulto: perspectiva da equipe multiprofissional. Rev. Psicol. Saúde [online]. 12(1), 157-170. http://dx.doi.org/10.20435/pssa.v12i1.734.

Knobel, E., Andreoli, P. B. A., \& Erlichman, M. R. (2008). Psicologia e humanização: assistência aos pacientes graves. São Paulo: Atheneu. Leopardi, M.T. (2001). Metodologia da pesquisa na saúde. Florianópolis: UFSC.

Minayo, M. C. S., Deslandes, S.F., \& Gomes, R. (2015). Pesquisa social: teoria, método e criatividade (29. Ed.). Petrópolis: Vozes. 
Research, Society and Development, v. 10, n. 8, e42210817390, 2021

(CC BY 4.0) | ISSN 2525-3409 | DOI: http://dx.doi.org/10.33448/rsd-v10i8.17390

Mongiovi, V. G., Anjos, R. C. C. B. L., Soares, S. B. H., \& Falcão, T. M. L. (2014). Reflexões conceituais sobre humanização da saúde: concepção de enfermeiros de Unidades de Terapia Intensiva. Rev Bras Enferm. 67(2), 306-311. https://doi.org/10.5935/0034-7167.20140042.

Neves, L., Gondim, A. A., Soares, S. C. M. R., Coelho, D. P., \& Pinheiro, J. A. M. (2018). O impacto do processo de hospitalização para o acompanhante familiar do paciente crítico crônico internado em Unidade de Terapia Semi-Intensiva. Esc. Anna Nery. 22(2), 1-8. doi: 10.1590/2177-9465-EAN-2017-0304.

Pessini, L., Bertachini, L., \& Barchifontaine, C. P. (2014). Bioética, cuidado e humanização: humanização dos cuidados de saúde e tributos de gratidão. São Paulo: Centro Universitário São Camilo.

Pinho, I. C., Siqueira, J. C. B. A., \& Pinho, L. M. O. (2006). As percepções do enfermeiro acerca da integralidade da assistência. Rev. eletrônica de enfermagem. 8(1), 42-51. https://doi.org/10.5216/ree.v8i1.945.

Ramos, F. J. S., Fumis, R. R. L., Azevedo, L. C. P., \& Schettino, G. (2014). Políticas de visitação em unidades de terapia intensiva no Brasil: um levantamento multicêntrico. Rev Bras Ter Intensiva. 26(4), 339-46. https://doi.org/10.5935/0103-507X.20140052.

Reis, C. C. A., Sena, E. L. S., \& Fernandes, M. H. (2016). Humanização do cuidado nas unidades de terapia intensiva: revisão integrativa. J. res.: fundam. care. [online]. 8(2), 4212-4222. https://doi.org/10.9789/2175-5361.2016.v8i2.4212-4222.

Reis, L. C. C., Gabarra, L. M., \& Moré, C. L. O. O. (2016). As repercussões do processo de internação em UTI Adulto na perspectiva de familiares. Temas psicol. [online]. 24(3), 815-828. http://dx.doi.org/10.9788/TP2016.3-03.

Silveira, R. E., \& Contim, D. (2015). Educação em saúde e prática humanizada da enfermagem em unidades de terapia intensiva: J. res.: fundam. care. 7(1), 2113-2122. doi: 10.9789/2175-5361.2015.v7i1.2113-2122.

Vedootto, D. O., \& Silva, R. M. (2010). Humanização com o familiar em uma Unidade de Terapia Intensiva: estudo descritivo. Online braz. j. nurs. [online]. 9(3), 1-15. ID: lil-717848 